replicated and extended the Gilson and Baddeley study and found no decay function, even to intervals of $60 \mathrm{sec}$.

If one is simply to compare those studies in which an STM decay function has been observed with those for which no such function has appeared, the box score clearly favors the latter group of findings. However, this does not seem like a satisfactory way of arriving at a conclusion.

\section{REFERENCES}

Bowers, R. L., Mollenhauer, M. S., \& LuXford, J. (1990). Shortterm memory for tactile and temporal stimuli in a shared-attention task. Perceptual \& Motor Skills, 70, 903-913.

Gilson, E. Q., \& BADDELEY, A. D. (1969). Tactile short-term memory. Quarterly Journal of Experimental Psychology, 21, 180-184.

Gordon, G. (ED.). (1978). Active touch. Oxford: Pergamon.

Johnson, N. S. (1976). A note on the use of $A^{\prime}$ as a measure of sensitivity. Journal of Experimental Child Psychology, 22, 530-531.
Kiphart, M. J., Auday, B. C., \& Cross, H. A. (1988). Short-term haptic memory for three-dimensional objects. Perceptual \& Motor Skills, 66, 79-91.

Klatzky, R. L., Lederman, S. J., \& Metzger, V. A. (1985). Identifying objects by touch: An "expert system." Perception \& Psychophysics, 37, 299-302.

MillaR, S. (1974). Tactile short-term memory by blind and sighted children. British Journal of Psychology, 65, 253-263.

SCHIFF, W., \& FoulKE, E. (1982). Tactual perception. Cambridge: Cambridge University Press.

Sullivan, E. V., \& TuRvey, M. T. (1972). Short-term retention of tactile stimulation. Quarterly Journal of Experimental Psychology, 24, 253-261.

(Manuscript received December 2, 1991.)

\title{
Workshop \\ Memory Strategies: Theory and Application \\ University of Trieste \\ November 6-7, 1992
}

A workshop on memory strategies will be held at the University of Trieste, November 6-7, 1992. The workshop is aimed at analyzing the role of cognitive strategies in storage and retrieval processes, and will focus on the main questions of the current debate: What is a "strategy"? What are the roles of attentional processes, metacognition factors, and intentions in adopting a memory strategy? What are the conditions that lead to the use of a specific strategy? What are the implications for a general model of the mind's architecture?

Invited speakers will include Graham Hitch, Asher Koriat, Michael Pressley, and Wolfgang Schneider. The workshop program will include oral presentations, guest speakers, and poster presentations.

The registration fee is 80,000 Italian Liras for participants and 40,000 Italian Liras for students. Payment of the fee should be addressed to PSY.CO 41554/0 Cassa di Risparmio di Trieste, Sede Centrale, Via Cassa di Risparmio 10, 34100 Trieste. 